\title{
Article \\ Role of Autologous Platelet Gel (APG) in Bone Healing: A Rabbit Study
}

\author{
Antonio Scarano ${ }^{1,2, *(\mathbb{D})}$, Francesco Inchingolo ${ }^{3}$, Biagio Rapone ${ }^{4} \mathbb{D}$, Alberta Greco Lucchina ${ }^{5}$, Erda Qorri ${ }^{6}(\mathbb{D}$ \\ and Felice Lorusso ${ }^{1}$ (D)
}

check for updates

Citation: Scarano, A.; Inchingolo, F.; Rapone, B.; Lucchina, A.G.; Qorri, E.; Lorusso, F. Role of Autologous Platelet Gel (APG) in Bone Healing: A Rabbit Study. Appl. Sci. 2021, 11, 395. https://doi.org/10.3390/app11010395

Received: 22 November 2020

Accepted: 31 December 2020

Published: 4 January 2021

Publisher's Note: MDPI stays neutral with regard to jurisdictional clai$\mathrm{ms}$ in published maps and institutional affiliations.

Copyright: () 2021 by the authors. Licensee MDPI, Basel, Switzerland. This article is an open access article distributed under the terms and conditions of the Creative Commons Attribution (CC BY) license (https:// creativecommons.org/licenses/by/ $4.0 /)$.
1 Department of Innovative Technologies in Medicine \& Dentistry, University of Chieti-Pescara, Via Dei Vestini, 31,66100 Chieti, Italy; drlorussofelice@gmail.com

2 Director of Specialization School of Oral Surgery, Department of Innovative Technologies in Medicine \& Dentistry, University of Chieti-Pescara, Via Dei Vestini, 31, 66100 Chieti, Italy

3 Department of Interdisciplinary Medicine, University of Bari “Aldo Moro", 70121 Bari, Italy; f.inchingolo@icloud.com

4 Department of Basic Medical Sciences, Neurosciences and Sense Organs, "Aldo Moro" University of Bari, 70121 Bari, Italy; biagiorapone79@gmail.com

5 Oral Surgery Unit, University of Eastern Piedmont, Via Lanino 1, 28100 Novara, Italy; albertagrecolucchina@gmail.com

6 Dean Faculty of Medical Sciences, Albanian University, Bulevardi Zogu I, 1001 Tirana, Albania; erda79@yahoo.com

* Correspondence: ascarano@unich.it; Tel.: +39-087-1355-4084; Fax: +39-087-1355-4099

\begin{abstract}
Purpose: The aim of the present study is to evaluate the influence and efficacy of autologous platelets on bone regeneration in a rabbit defects model. Materials and Methods: A total of 12 critical size tibial defects were produced in six New Zealand rabbits: A total of six defects were filled with autologous platelet gel (APG) and six defects were maintained as untreated controls. No membranes were used to cover the bone osteotomies. The histology and histomorphometry were performed at four weeks on retrieved samples of both groups. Results: No complications were reported in any of the animals nor for the defects produced. A significantly higher lamellar and woven bone percentage was reported for the APG group with a lower level of marrow spaces $(p<0.05)$. Evidence of newly formed bone was found in the superficial portion of the bone defect of APG samples where no aspects of bone resorption were observed. Conclusions: The evidence of the present research revealed that APG increases new bone formation restricted to the cortical portion and induces more rapid healing in rabbit bone defects than in untreated defects.
\end{abstract}

Keywords: autologous platelet gel; new bone formation; bone repair; platelet derivates

\section{Introduction}

There is a need to find more efficient surgical procedures and biomaterials for bone regeneration. Biomaterials are available in many different sizes, porosity, and quantity [1], and are utilized for the treatment of bone loss due to tooth extraction or inflammation [2]. If compared to autogenous bone, the substitutes are cell-free and characterized by an increased osteointegration period and a lower level of biological activity. Nowadays, bone grafts represent a useful alternative option requiring a lower quantity of new bone formation when compared to autogenous bone [3]. Several studies have been published on updates and the improved performance of various types of bone grafts for bone regeneration. Different typologies of materials and methods have been proposed for improving bone healing: Autologous grafts; demineralized and mineralized freeze-dried allografts; anorganic bovine and porcine bone; collagenated substitutes, coralline calcium carbonate; bioglasses; hydroxyapatite; polylactidepolyglycolide-derivate grafts; synthetic polymers; and calcium sulphate [3]. They are commercially available in the form of particles, cement pastes, gels, and blocks of osteoconductive and osteoinductive biomaterials for bone 
augmentation and hard tissue reconstruction. The good qualities of biomaterials are osteoinduction and osteoconduction, and mechanical resistance under functional loads with easy management in clinical practice. Autologus bone is believed to be the "gold standard" because it promotes angiogenesis and has osteogenetic qualities, and is also osteoinductive, osteoconductive, with no risk of infection transmission [4]. The use of autologus bone is, however, related to some disadvantages, such as higher morbidity and complications related to the management of a donor site and a limited availability of graft [5]. Bone grafts have been proposed for bone augmentation for maintaining space and scaffolding between the bone surface and periosteum/membranes. Many bone graft alternatives and adjuvant, in the form of substitutes and recombinant human growth factors, have been reported in the literature [6]. The use of platelet concentrates is on the increase in clinical practice and are used alone or mixed with biomaterials. Choukroun et al. (2001) [7], described platelet rich fibrin (L-PRF), which is a second generation platelet concentrate that contains fibrin and platelet. It eases and guides angiogenesis, traps the circulating stem cells [8], and offers wound protection through epithelial coverage [9]. It is obtained after slow polymerization of the fibrinogen and contains cytokines and many growth factors that are released into the wound site over a long period [10]. This fibrin matrix has been used with success for improving bone regeneration in implants in the early healing stages after implant placement [11]. In addition, autologous cancellous bone combined with autologous platelets improved bone healing in an in vivo critical-size cylindrical defect study [12]. Furthermore, the combination collagene 1 and PRP-enhanced bone healing in a critical-size defect in a pig model [13]. Therefore, the utilization of scaffolds for growth factor delivery and cells has drawn a considerable amount of interest in bone augmentation [14]. In recent years, there has been an increased interest in growth factors obtained from autologous platelets and their use. The aim of this study is to evaluate the influence of autologous platelet gel APG on bone healing in a rabbit model.

\section{Materials and Methods}

In this study, 6 New Zealand white mature male (age $~ 11$ weeks and weighing around $\sim 2.5 \mathrm{kgs}$ ) were used. The local Ethics Committee of Albania University approved the study and it was carried out in accordance with the relevant guidelines and regulations of Albanian law on animal research. The in-vivo study followed the guidelines (national and international) for animal treatment and conformed to the ARRIVE guidelines. The rabbits were housed under veterinary supervision in standardized rabbit cages (only one rabbit per cage), maintained in a laboratory environment with a controlled temperature $\left(21-24.5^{\circ} \mathrm{C}\right)$, humidity (43-56\%), and 12-h light and dark cycles. All animals had ad libitum access to a standard rabbit chow diet and water. The leg was shaved and disinfected using Povidoneiodine $10 \%$ solution (SALVAVIDAS PHARMACEUTICAL PVT. LTD. Surat, India). The rabbits were anesthetized with intramuscular injections of fluanizone $(0.7 \mathrm{mg} / \mathrm{kg}$ b.wt.) and diazepam ( $1.5 \mathrm{mg} / \mathrm{kg}$ b.wt.), and local anaesthesia were applied using $1 \mathrm{~mL}$ of $2 \%$ aticaine/adrenalin solution (Pierrel Pharma, Italy). After identification, a longitudinal incision was performed in the tibia and dissection of the skin flap exposed the bone. A conventional dental handpiece with a physio-dispenser (Vario-Surgery NSK, Tochigi, Japan) was used for bone defect preparation with drills cooled by saline irrigation. In each rabbit tibia, twocritical-size circular defects (6-mm diameter) were created (Figure 1). 

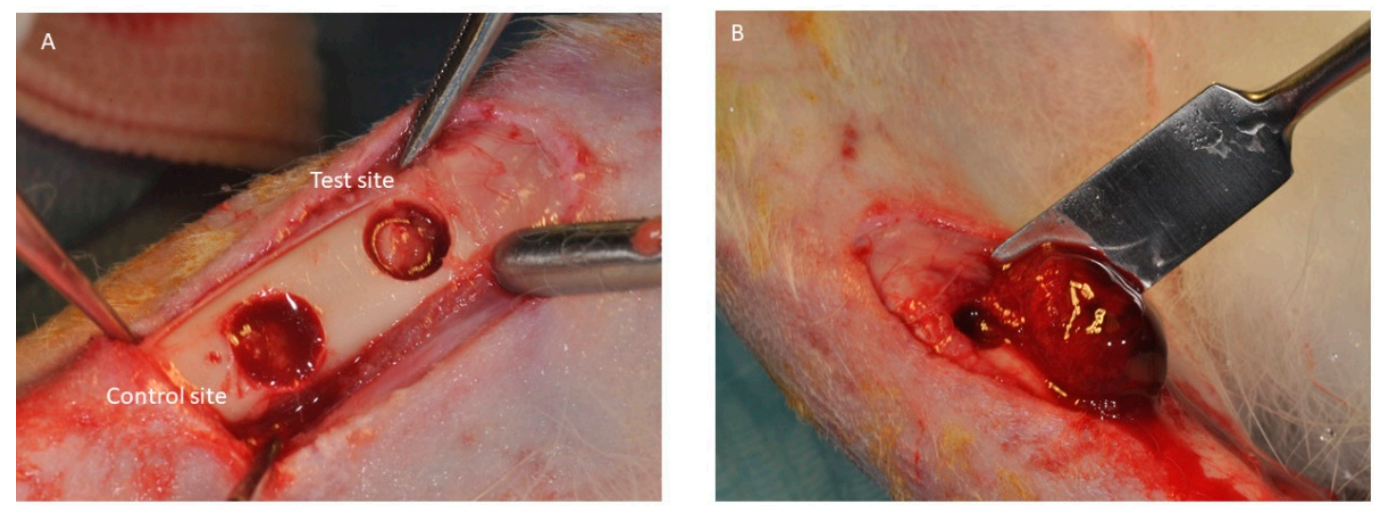

Figure 1. (A) Two bone defects in the rabbit tibia. (B) The test bone defect filled with autologous platelet gel (APG).

For each tibia, one defect was filled with APG while the second defect was left empty and was used as control. The defect filled with APG was randomized to avoid the influence of the dimension of the tibia on the healing process. No membrane was used for covering the bone defect. The periosteum and fascia were sutured with resorbable suture (Glicofil Lac $^{\circledR}$, Assut, Magliano dei Marsi, Italy) and the skin with silk (Assusilk ${ }^{\circledR}$, Assut, Magliano dei Marsi, Italy). No deaths or other complications occurred in the postoperative period. All the rabbits were sacrificed with an overdose of intravenous pentobarbital, after 4 weeks. A total of 12 specimens ( 6 tests and 6 controls) were retrieved

\subsection{Specimen Processing}

The specimens were first washed in saline solution and after $10 \mathrm{~min}$ were put into $4 \%$ paraformaldehyde and $0.1 \%$ glutaraldehyde in a $0.15 \mathrm{M}$ cacodylate buffer al $4{ }^{\circ} \mathrm{C}$ and $\mathrm{pH} 7.4$, for fixation of the tissues and for processing to achieve specimen histology. SCAN 1 Automated System (Pescara, Italy) was used to achieve the sections containing the defects. The specimens were dehydrated in ascending concentrations of ethyl alcohol rinses, from $60 \%$ to $100 \%$, and embedded in a glycolmethacrylate resin (Technovit 7200 VLC, Kulzer, Wehrheim, Germany). This resin was polymerized with UV light and the block was sectioned, along the longitudinal axis, with a diamond disc at about $140 \mu \mathrm{m}$ then ground down to about $40 \mu \mathrm{m}$ with a specially designed grinding machine to obtain 3 slides for each specimen. Toluidine blue and acid fuchsin were used to stain the specimens as previously described [15]. The slides were then observed through normal transmitted light by a Nikon microscope ECLIPSE (Nikon, Tokyo, Japan). The microscope was connected to a high-resolution video camera with a high definition monitor and a computer workstation (Notebook Toshiba Satellite pro r50-c-15w). A histometry software package for image capturing was used for morphometric analysis by digital image-analysis (NIS-Elements AR 3.0 software, Nikon, Minato, Japan). The aspects of the newly formed and mature bone could be classified due to the histological color of the tissues (light red = old matrix, dark red = new matrix) and their quantity was expressed in percentage (Mean \pm SD). Toluidine blue and acid fuchsin staining revealed cell types and patterns of hard and soft tissue present in the defects. Newly formed bone was distinguishable from the original bone due to a higher intensity of staining in the new bone. For the histomorphometric analysis, a region was selected for a representative measurement. The selected region of interest (ROI-1) $6000 \times 2500 \mu$ included the whole defect area containing the newly formed bone. For the evaluation of medullary space, a region of interest (ROI-2) $3000 \times 3000 \mu$ containing the central portion of tibia was selected. Newly formed bone was distinguishable from the original bone due to a higher intensity of staining in the new bone. After acquiring the image to be analyzed, the first step in software analysis was to identify the region of interest manually ROI, using the overlay drawing tools. Next, the bone tissue was identified by an interactive threshold in the hue-saturation-brightness (HSB) colour space. If necessary, an option can be used that allows the use of a hysteresis threshold 
for the saturation band. The small sectioning artefacts, such as cracks, can be removed using simple binary close ('close cracks') and hole-fill operations. Small fragments in the image are removed using an erode-reconstruct algorithm. The resulting image allowed for the quantitative measurement of the mineralized bone and quantity of marrow space and red intensity was digitally image-analyzed. The data obtained from the analyses were transformed into absolute values of pixels and then to percentages.

The following measurements were taken: Lamellar bone surface: Expressed as percentages of the region of interest; woven bone surface: Expressed as percentages of the region of interest; and marrow space surface: Expressed as percentages of the region of interest.

\subsection{Autologous Platelet Gel (APG) Preparation}

The blood of a healthy donor was stored as follows: Disposable kits for autologus Platelet preparation were used. These kits, including: $4 \times 9 \mathrm{~mL}$ white vials for fractionation, $4 \times 9 \mathrm{~mL}$ blue vials with anticoagulant, $2 \times 9 \mathrm{~mL}$ red vials with serum activator, $1 \times 5 \mathrm{~mL}$ syringe, $1 \times 1 \mathrm{~mL}$ activator syringe, and 1 butterfly needle $21 \mathrm{G}$, for blood assemblage with preassembled holder with luer lock attachment. One red vial with serum activator was used for each rabbit and was filled with the arterial blood by a butterfly needle $21 \mathrm{G}$ for blood collection with preassembled holder with luer lock attachment (Figure 2). When the vial tube was filled, the needle was removed from the rabbit, using a swift backward motion. The vial was positioned in a device specifically designed for separating blood components (GF-ONE, Ubgen Padova Italy). The medical device is automatically controlled by a microprocessor that provides a custom scheduling of set speed (RPM) or relative centrifugal force (RCF) and centrifugation time. The centrifuge has a microprocessor that allows users to set speed and automatically have the RCF value and vice-versa. The red vials were centrifuged at 1751 RPM (246 RCF) for $7 \mathrm{~min}$ at room temperature, producing some platelet and fibrinogen gel. The APG was transferred into a glass container and used to fill the bone defect. In this study, we used glass because it is a potent activator of platelets without anticoagulants, bovine thrombin, or any other gelling agent [16].

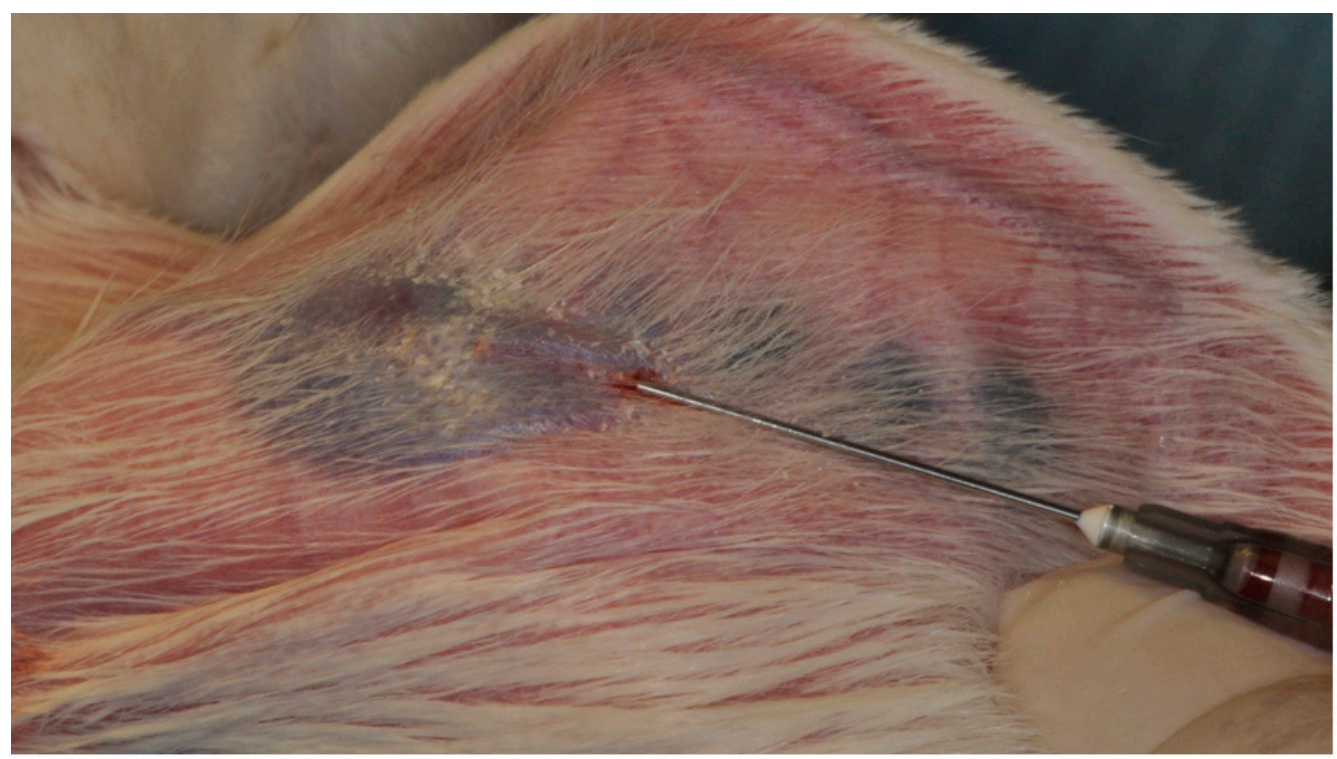

Figure 2. During blood collection from the auricular vein.

\subsection{Statistical Evaluation}

A power analysis was done through clinical software, (http:/ / clincalc.com/stats / samplesize.aspx), for determining the number of bone defects needed to achieve statistical significance for a quantitative measurement of the new bone. A calculation model was adopted for dichotomous variables (yes/no effect) by putting the effect incidence designed 
to caution the reasons $10 \%$ for controls and $95 \%$ for treated. The optimal number of samples for analysis was 6 rabbits. The normal distribution of the study data was evaluated by the Shapiro-Wilks test and the statistical differences between test and control groups were analyzed by $t$ Student test. The level of significance was set for $p$-value $<0.05$. The study data were collected and statistically analyzed by the use of the dedicated software package Graphpad 8 (Prism, San Diego, CA USA).

\section{Results}

\subsection{Control Defect}

Macroscopically, the bone defect was still visible. The percentages of woven bone were evaluated. Bone morphology presented differentiated cellular lines specific of bone formation, such as osteoblasts, osteocytes but also osteoid and blood vessels. An initial formation of immature bone extending from the periphery of the bone defect could be seen. The rest of the bone cavity contained marrow space without a pathological inflammatory reaction. The mild inflammatory reaction was characterized by a foci of lymphocytes distributed around the periphery of the cavity. The tissues present in the defect were composed of $8 \pm 3 \%$ of lamellar bone, $28 \pm 1 \%$ of woven bone, and $59 \pm 3 \%$ of medullary spaces (Figures 3-5 and Table 1).
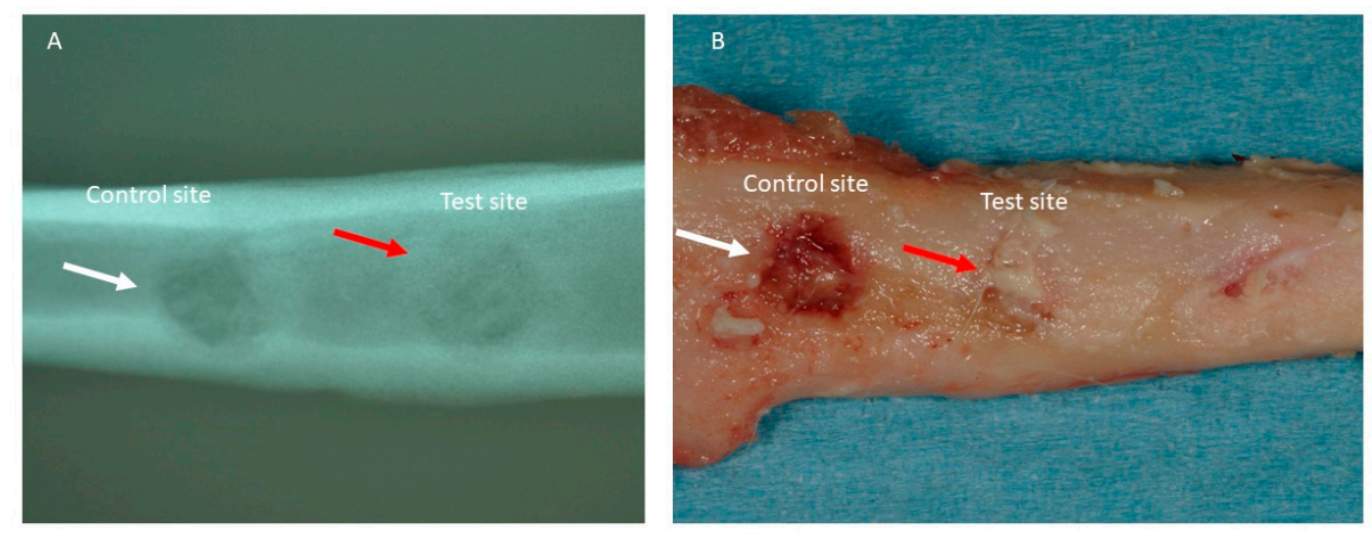

Figure 3. (A). The test bone defect appears more radiopaque. (B). The bone defect appears completely healed and filled up by tissues.
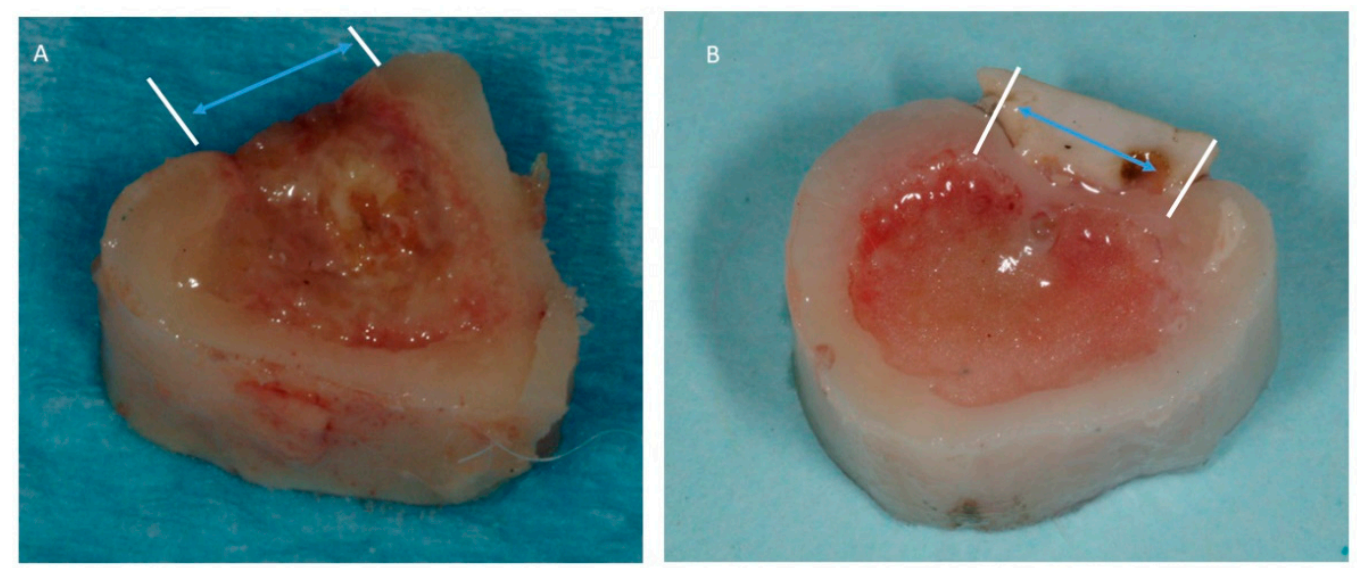

Figure 4. (A). Control bone defect is not filled by new bone. The test bone defect appears empty. (B). The bone defect appears filled up by hard tissues only in the cortical portion. 

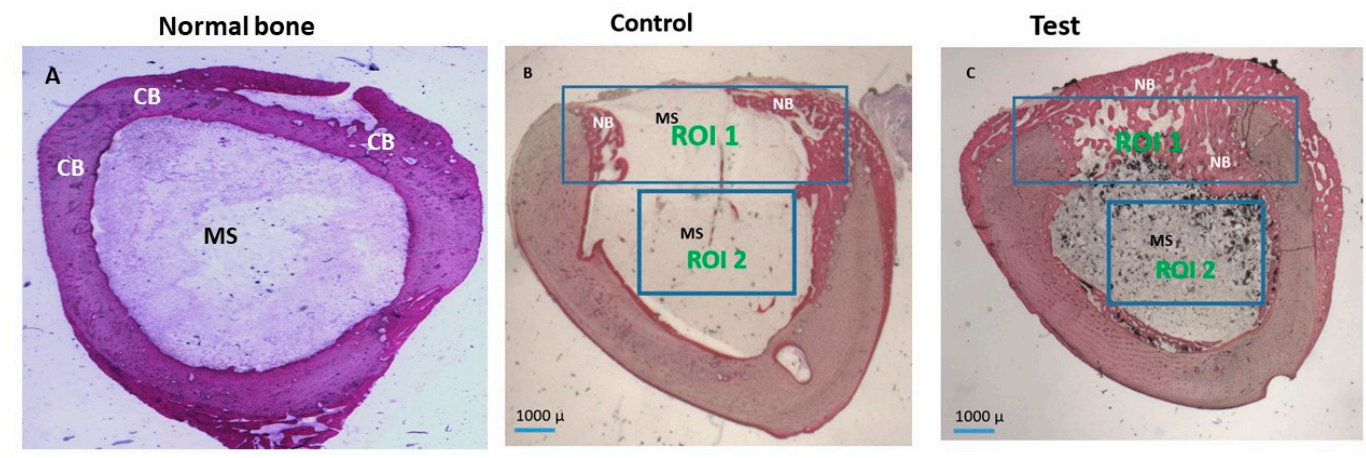

Figure 5. (A). Histological section of normal bone of rabbit tibia, cortical bone (CB), and medullary space (MS). (B). The bone defect is only half filled by new bone (NB) (ROI1) and the other half is the medullary space (MS) (ROI2). Acid fuchsin-toluidine blue 12X. (C). New bone (NB) filled the bone defect only in the cortical portion. No new bone was observed in the central portion of the defect (MS) (ROI2). Acid fuchsin-toluidine blue 12X.

Table 1. Summary of the lamellar bone, woven bone, and medullary space of control group and APG group after four weeks ( $t$ Student test).

\begin{tabular}{|c|c|c|c|c|c|c|}
\hline & \multicolumn{4}{|c|}{ Control Group } & \multicolumn{2}{|c|}{ APG Group } \\
\hline & $\begin{array}{l}\text { Lamellar } \\
\text { Bone }\end{array}$ & $\begin{array}{c}\text { Woven } \\
\text { Bone }\end{array}$ & $\begin{array}{l}\text { Medullary } \\
\text { Space }\end{array}$ & $\begin{array}{l}\text { Lamellar } \\
\text { Bone }\end{array}$ & $\begin{array}{c}\text { Woven } \\
\text { Bone }\end{array}$ & $\begin{array}{l}\text { Medullary } \\
\text { Space }\end{array}$ \\
\hline $\begin{array}{l}\text { Mean } \pm \\
\text { Standard } \\
\text { Dev. }\end{array}$ & $8 \pm 3 \%$ & $28 \pm 1 \%$ & $59 \pm 3 \%$ & $18 \pm 3 \%$ & $52 \pm 1 \%$ & $26 \pm 4 \%$ \\
\hline$p$ value & $p<0.05$ & $p<0.05$ & $p<0.05$ & $p<0.05$ & $p<0.05$ & $p<0.05$ \\
\hline
\end{tabular}

\subsection{Test Defect (Bone Defect Filled with APG)}

Macroscopically, the bone defect appears completely healed. Bone formation was observed with well differentiated cells and mineralized matrix: Osteoblasts, osteoid, osteocytes, and blood vessels in all bone defects especially in the central portion of the defect. Bone formation extending from the margin of the bone defect was recorded. New bone was also recorded in the central portion of bone defect. Marrow space tissue still occupied a small portion of the defect area. A few bone trabecular from the periosteum were observed. No bone resorb was recorded. The bone defect was composed of $18 \pm 3 \%$ of lamellar bone, $52 \pm 1 \%$ of woven bone, and $26 \pm 4 \%$ of marrow spaces (Figures $3-5$ and Table 1 ).

\subsection{Statistical Evaluation}

A statistically significant difference was evident in the percentage of new bone between the Control and Test site. The average and SD values of the new lamellar bone, woven bone, and medullary space are presented in Table 1 and Figure 6. 


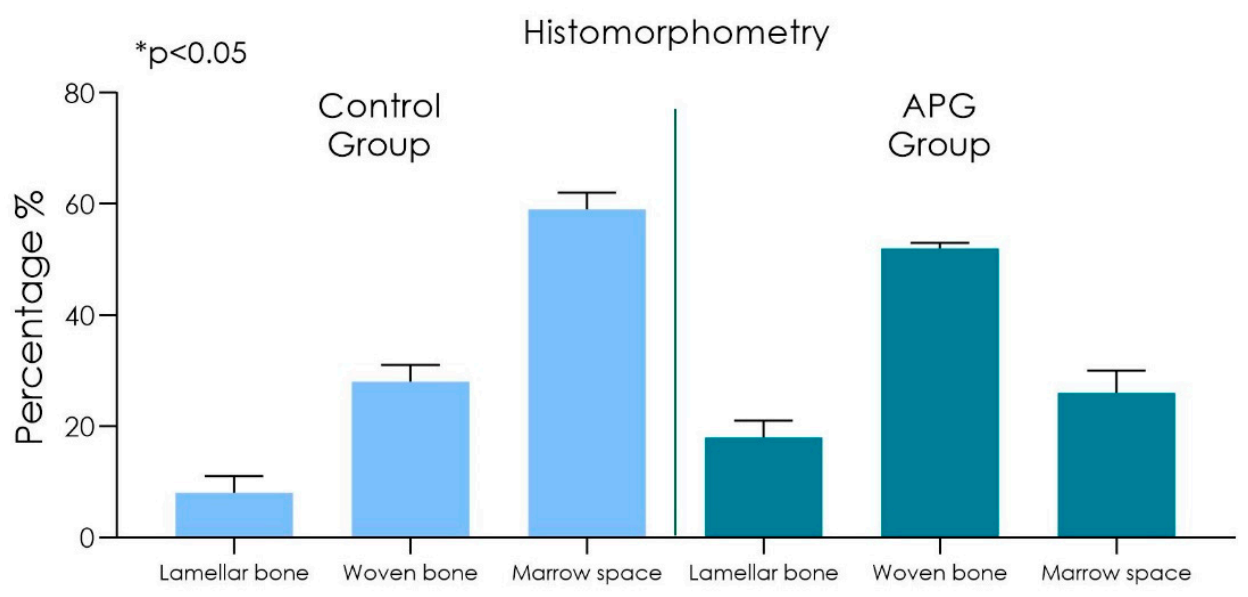

Figure 6. Graph chart of the lamellar bone, woven bone, and medullary space of control group and APG group after four weeks ( $t$ Student test), ${ }^{*} p<0.05$.

\section{Discussion}

In this study we observed that APG induced a higher quantity of lamellar bone and woven bone within the tibia defect as compared to the control. In this research, we aimed to further investigate bone regeneration enhanced by APG in a rabbit model using histological parameters. We calculated the percentages of marrow space and new bone formation in the tibia defects filled with APG. The results showed that the percentage of formation of new bone and marrow space was different between the two groups. Precisely, we found that, although some percentage of new bone in the APG group was higher than that of the control, when comparing the woven bone, we found that APG increased bone formation significantly more than in the control site. The present findings, when comparing the data obtained on bone formation, showed that the positive role of APG in bone regeneration is due to the formation of mature (lamellar) bone restricted to the cortical bone. These results confirm previous observations on the role of concentrate platelet on bone healing. APG possesses osteocoinductive properties and is capable of providing a three-dimensional structure for bone healing, thus, it may be speculated that concentrate platelet and fibrin may favor the natural process of bone formation and can provide a microenvironment to produce osteogenic activity. This hypothesis is also confirmed by data showing that APG showed greater osteoconductivity and had a greater percentage of woven bone when compared to the control site. Probably, fibrin matrix could hold many cytokines and growth factors and release them in the wound site for a prolonged time. In fact some authors find that fibrin matrix releases growth factors in the wound site over a prolonged time and accelerates bone repair $[10,17]$. However, given the low number of rabbits used in the study, further studies are necessary to validate this hypothesis. Several authors have investigated the action of fibrin matrix in bone regeneration, either alone or in combination with other graft materials [18]. Platelet derivates have been used in bone regeneration to improve bone quality and bone quantity $[19,20]$. In fact, autologous platelet derivate, liberates different growth factors, such us vascular endothelial growth factor (VEGF), growth factor (PDGF) transforming growth factor beta (TGF- $\beta$ ), and others. The autologous platelet derivate gradually releases growth factors from the APG matrix and this liberation can last for up to seven days, which may improve tissue healing and better results in bone regeneration procedures [21-25]. In the present study, we chose New Zealand Rabbits due to the possibility of collecting an amount of blood as in humans, their bone turnover rate, and the ease of handling and availability, making them an appropriate model for the evaluation of bone regeneration. This model is frequently used for evaluating bone healing in implantology [26]. It was decided to evaluate the bone regeneration after four weeks because the rabbit has a high rate of bone turnover and reaches bone maturation after eight weeks [27]. In the present study, at the four-week healing interval, the APG group showed significantly more new bone formation in the cortical portion than 
control. In the present study we did not evaluate the differences from the other $\mathrm{CP}$ and our results are similar to Ehrenfest et al. that reported the platelet concentrate increases new bone formation [10]. The use of fibrin matrix solely as a filling material for critical bone defects remains controversial. Ozdemir et al. reported positive effects of L-PRF when used in conjunction with titanium barriers [28]. The animal study conducted by Kim et al. reported increased bone mineral density and bone volume in calvaria bone defects of rabbits treated with PRF already after six weeks, with similar results to two other platelets concentrates tested: PRP and Concentrated Growth Factor [29]. So in the present study we have observed similar results to that of PRF. While Knapen et al. observed that L-PRF did not provide any additional effect on the quantity and quality of bone during guided bone healing over a period of 12 weeks [30]. Frequently, platelet concentrates have been used mixed with bone graft to promote bone regeneration [31]. The growth factors present in APG have been shown to induce bone formation and enhance fibroblast proliferation when mixed with hydroxyapatite [32]. Furthermore, fibrin matrix increases the rate of collagen formation, tissue vascularity, and mitosis of mesenchymal stem cells, endothelial cells, and osteoblasts [17]. APG promotes adhesiveness and tensile strength for clot stabilization, especially in bone defects. Our results showed that the treatment of bone defects by APG application significantly increases the healing dynamics, at least in terms of new bone formation. However, the role of fibrin matrix in bone defect is controversial, Faot et al. reported that the L-PRF did not influence bone formation when it was used in non-critical bone defects in rabbit tibia at 28 days [33]. Motta Padilha et al. found in a rat model that LPRF reduced inflammatory response and enhanced bone neoformation [34]. Many studies showed that L-PRF mixed with scaffold improved bone repair [35-37]. In conclusion, there is a clear positive effect of APG on bone healing with enhanced bone tissue repair restricted to the cortical bone of critical size defects in rabbit tibia during our four week experiment, while it did not enhance bone tissue repair in the medullary space. The present study has a major limitation: The treated and control defects were on the same tibia, therefore there was a possibility of the growth factors generating from the APG site migrating to the empty site. While migration of the fibrin matrix is not possible, it is probable that the fibrin matrix plays an important role in bone healing. Another limit is that the present study has investigated the role of APG on bone healing by a histomorphometry approach without an evaluation of mechanical strength and the localized or systemic concentration of the growth factors, which ones, and the duration of their increases.

Author Contributions: Conceptualization, A.S.; methodology, A.S.; software, A.S.; validation, A.S.; formal analysis, A.S.; investigation, E.Q., A.S., F.L.; resources, A.S.; data curation, A.S., F.L.; writingoriginal draft preparation, A.S.; writing-review and editing, A.S., F.L.; visualization, A.S., B.R., A.G.L., F.I.; supervision, A.S., B.R., A.G.L., F.I., E.Q.; project administration, A.S.; funding acquisition, A.S. All authors have read and agreed to the published version of the manuscript.

Funding: This research received no external funding.

Institutional Review Board Statement: The study has been approved by the local Ethics Committee of Albania University, Tirana, Albania.

Informed Consent Statement: Not applicable.

Data Availability Statement: All experimental data to support the findings of this study are available contacting the corresponding author upon request. The authors have annotated the entire data building process and empirical techniques presented in the paper.

Acknowledgments: The authors declare no acknowledgement for the present research.

Conflicts of Interest: The authors declare no conflict of interest.

\section{References}

1. Scarano, A.; Carinci, F.; Assenza, B.; Piattelli, M.; Murmura, G.; Piattelli, A. Vertical ridge augmentation of atrophic posterior mandible using an inlay technique with a xenograft without miniscrews and miniplates: Case series. Clin. Oral Implants Res. 2011, 22, 1125-1130. [CrossRef] [PubMed] 
2. Scarano, A.; Di Domizio, P.; Petrone, G.; Iezzi, G.; Piattelli, A. Implant periapical lesion: A clinical and histologic case report. J. Oral Implantol. 2000, 26, 109-113. [CrossRef]

3. Scarano, A.; Degidi, M.; Iezzi, G.; Pecora, G.; Piattelli, M.; Orsini, G.; Caputi, S.; Perrotti, V.; Mangano, C.; Piattelli, A. Maxillary sinus augmentation with different biomaterials: A comparative histologic and histomorphometric study in man. Implant Dent. 2006, 15, 197-207. [CrossRef] [PubMed]

4. Myeroff, C.; Archdeacon, M. Autogenous bone graft: Donor sites and techniques. J. Bone Joint Surg. Am. 2011, 93, 2227-2236. [CrossRef] [PubMed]

5. Gazdag, A.R.; Lane, J.M.; Glaser, D.; Forster, R.A. Alternatives to Autogenous Bone Graft: Efficacy and Indications. J. Am. Acad. Orthop. Surg. 1995, 3, 1-8. [CrossRef] [PubMed]

6. Devi, R.; Dixit, J. Clinical Evaluation of Insulin like Growth Factor-I and Vascular Endothelial Growth Factor with Alloplastic Bone Graft Material in the Management of Human Two Wall Intra-Osseous Defects. J. Clin. Diagn. Res. 2016, 10, ZC41-ZC46. [CrossRef]

7. Choukroun, J.; Adda, F.; Schoeffer, C.; Vervelle, A. PRF: An opportunity in perio-implantology. Implantodontie 2000, 42, 55-62.

8. Brown, A.C.; Barker, T.H. Fibrin-based biomaterials: Modulation of macroscopic properties through rational design at the molecular level. Acta Biomater. 2014, 10, 1502-1514. [CrossRef]

9. Gassling, V.; Douglas, T.; Warnke, P.H.; Açil, Y.; Wiltfang, J.; Becker, S.T. Platelet-rich fibrin membranes as scaffolds for periosteal tissue engineering. Clin. Oral Implants Res. 2010, 21, 543-549. [CrossRef]

10. Dohan Ehrenfest, D.M.; de Peppo, G.M.; Doglioli, P.; Sammartino, G. Slow release of growth factors and thrombospondin-1 in Choukroun's platelet-rich fibrin (PRF): A gold standard to achieve for all surgical platelet concentrates technologies. Growth Factors Chur Switz. 2009, 27, 63-69. [CrossRef]

11. DENTAL SUPPLEMENT; Testori, T.; Panda, S.; Clauser, T.; Scaini, R.; Zuffetti, F.; Capelli, M.; Taschieri, S.; Mortellaro, C.; Del Fabbro, M. Short implants and platelet-rich fibrin for transcrestal sinus floor elevation: A prospective multicenter clinical study. J. Biol. Regul. Homeost. Agents 2019, 33, 121-135. [PubMed]

12. Hakimi, M.; Jungbluth, P.; Sager, M.; Betsch, M.; Herten, M.; Becker, J.; Windolf, J.; Wild, M. Combined use of platelet-rich plasma and autologous bone grafts in the treatment of long bone defects in mini-pigs. Injury 2010, 41, 717-723. [CrossRef]

13. Goyal, B.; Tewari, S.; Duhan, J.; Sehgal, P.K. Comparative evaluation of platelet-rich plasma and guided tissue regeneration membrane in the healing of apicomarginal defects: A clinical study. J. Endod. 2011, 37, 773-780. [CrossRef] [PubMed]

14. Scarano, A.; Crincoli, V.; Di Benedetto, A.; Cozzolino, V.; Lorusso, F.; Podaliri Vulpiani, M.; Grano, M.; Kalemaj, Z.; Mori, G.; Grassi, F.R. Bone Regeneration Induced by Bone Porcine Block with Bone Marrow Stromal Stem Cells in a Minipig Model of Mandibular "Critical Size" Defect. Stem Cells Int. 2017, 2017, 9082869. [CrossRef] [PubMed]

15. Piattelli, A.; Scarano, A.; Piattelli, M. Detection of alkaline and acid phosphatases around titanium implants: A light microscopical and histochemical study in rabbits. Biomaterials 1995, 16, 1333-1338. [CrossRef]

16. Hartwig, J.H. Mechanisms of actin rearrangements mediating platelet activation. J. Cell Biol. 1992, 118, 1421-1442. [CrossRef]

17. Kumar, R.V.; Shubhashini, N. Platelet rich fibrin: A new paradigm in periodontal regeneration. Cell Tissue Bank. 2013, 14, 453-463. [CrossRef]

18. Kim, D.-S.; Lee, W.-J.; Choi, S.-C.; Lee, S.-S.; Heo, M.-S.; Huh, K.-H.; Kim, T.-I.; Yi, W.-J. Comparison of dental implant stabilities by impact response and resonance frequencies using artificial bone. Med. Eng. Phys. 2014, 36, 715-720. [CrossRef]

19. Karayürek, F.; Kadiroğlu, E.T.; Nergiz, Y.; Coşkun Akçay, N.; Tunik, S.; Ersöz Kanay, B.; Uysal, E. Combining platelet rich fibrin with different bone graft materials: An experimental study on the histopathological and immunohistochemical aspects of bone healing. J. Cranio-Maxillofac. Surg. 2019, 47, 815-825. [CrossRef]

20. Dragonas, P.; Katsaros, T.; Avila-Ortiz, G.; Chambrone, L.; Schiavo, J.H.; Palaiologou, A. Effects of leukocyte-platelet-rich fibrin (L-PRF) in different intraoral bone grafting procedures: A systematic review. Int. J. Oral Maxillofac. Surg. 2019, 48, 250-262. [CrossRef]

21. Miron, R.J.; Dham, A.; Dham, U.; Zhang, Y.; Pikos, M.A.; Sculean, A. The effect of age, gender, and time between blood draw and start of centrifugation on the size outcomes of platelet-rich fibrin (PRF) membranes. Clin. Oral Investig. 2019, 23, $2179-2185$. [CrossRef] [PubMed]

22. Cortellini, S.; Castro, A.B.; Temmerman, A.; Van Dessel, J.; Pinto, N.; Jacobs, R.; Quirynen, M. Leucocyte- and platelet-rich fibrin block for bone augmentation procedure: A proof-of-concept study. J. Clin. Periodontol. 2018, 45, 624-634. [CrossRef] [PubMed]

23. Miron, R.J.; Zucchelli, G.; Pikos, M.A.; Salama, M.; Lee, S.; Guillemette, V.; Fujioka-Kobayashi, M.; Bishara, M.; Zhang, Y.; Wang, H.-L.; et al. Use of platelet-rich fibrin in regenerative dentistry: A systematic review. Clin. Oral Investig. 2017, 21, $1913-1927$. [CrossRef] [PubMed]

24. Castro, A.B.; Meschi, N.; Temmerman, A.; Pinto, N.; Lambrechts, P.; Teughels, W.; Quirynen, M. Regenerative potential of leucocyte- and platelet-rich fibrin. Part A: Intra-bony defects, furcation defects and periodontal plastic surgery. A systematic review and meta-analysis. J. Clin. Periodontol. 2017, 44, 67-82. [CrossRef] [PubMed]

25. Castro, A.B.; Meschi, N.; Temmerman, A.; Pinto, N.; Lambrechts, P.; Teughels, W.; Quirynen, M. Regenerative potential of leucocyte- and platelet-rich fibrin. Part B: Sinus floor elevation, alveolar ridge preservation and implant therapy. A systematic review. J. Clin. Periodontol. 2017, 44, 225-234. [CrossRef]

26. Scarano, A.; Crocetta, E.; Quaranta, A.; Lorusso, F. Influence of the Thermal Treatment to Address a Better Osseointegration of Ti6Al4V Dental Implants: Histological and Histomorphometrical Study in a Rabbit Model. BioMed Res. Int. 2018, 2018, 2349698. [CrossRef]

27. Scarano, A.; Piattelli, A.; Quaranta, A.; Lorusso, F. Bone Response to Two Dental Implants with Different Sandblasted/Acid-Etched Implant Surfaces: A Histological and Histomorphometrical Study in Rabbits. BioMed Res. Int. 2017, 2017, 8724951. [CrossRef] 
28. Ozdemir, H.; Ezirganli, S.; Isa Kara, M.; Mihmanli, A.; Baris, E. Effects of platelet rich fibrin alone used with rigid titanium barrier. Arch. Oral Biol. 2013, 58, 537-544. [CrossRef] [PubMed]

29. Kim, T.-H.; Kim, S.-H.; Sándor, G.K.; Kim, Y.-D. Comparison of platelet-rich plasma (PRP), platelet-rich fibrin (PRF), and concentrated growth factor (CGF) in rabbit-skull defect healing. Arch. Oral Biol. 2014, 59, 550-558. [CrossRef]

30. Knapen, M.; Gheldof, D.; Drion, P.; Layrolle, P.; Rompen, E.; Lambert, F. Effect of leukocyte- and platelet-rich fibrin (L-PRF) on bone regeneration: A study in rabbits. Clin. Implant Dent. Relat. Res. 2015, 17 (Suppl. S1), e143-e152. [CrossRef]

31. Rezuc, A.; Saavedra, C.; Maass, R.; Poblete, C.; Nappe, C. Histological comparison of DBBM and platelet rich fibrin for guided bone regeneration in a rabbit model. J. Oral Biol. Craniofac. Res. 2020, 10, 287-293. [CrossRef] [PubMed]

32. Scarano, A.; Valbonetti, L.; Marchetti, M.; Lorusso, F.; Ceccarelli, M. Soft Tissue Augmentation of the Face With Autologous Platelet-Derived Growth Factors and Tricalcium Phosphate. Microtomography Evaluation of Mice. J. Craniofac. Surg. 2016, 27, 1212-1214. [CrossRef] [PubMed]

33. Faot, F.; Deprez, S.; Vandamme, K.; Camargos, G.V.; Pinto, N.; Wouters, J.; van den Oord, J.; Quirynen, M.; Duyck, J. The effect of L-PRF membranes on bone healing in rabbit tibiae bone defects: Micro-CT and biomarker results. Sci. Rep. 2017, 7, 46452. [CrossRef] [PubMed]

34. Padilha, W.S.M.; Soares, A.B.; Navarro-Junior, H.; Joly, J.C.; Peruzzo, D.C.; Napimoga, M.H.; Martinez, E.F. Histologic Evaluation of Leucocyte- and Platelet-Rich Fibrin in the Inflammatory Process and Repair of Noncritical Bone Defects in the Calvaria of Rats. Int. J. Oral Maxillofac. Implants 2018, 33, 1206-1212. [CrossRef]

35. do Lago, E.S.; Ferreira, S.; Garcia, I.R.; Okamoto, R.; Mariano, R.C. Improvement of bone repair with l-PRF and bovine bone in calvaria of rats. histometric and immunohistochemical study. Clin. Oral Investig. 2020, 24, 1637-1650. [CrossRef]

36. Oliveira, M.R.; deC Silva, A.; Ferreira, S.; Avelino, C.C.; Garcia, I.R.; Mariano, R.C. Influence of the association between plateletrich fibrin and bovine bone on bone regeneration. A histomorphometric study in the calvaria of rats. Int. J. Oral Maxillofac. Surg. 2015, 44, 649-655. [CrossRef]

37. Lee, J.-B.; Lee, J.-T.; Hwang, S.; Choi, J.-Y.; Rhyu, I.-C.; Yeo, I.-S.L. Leukocyte- and platelet-rich fibrin is an effective membrane for lateral ridge augmentation: An in vivo study using a canine model with surgically created defects. J. Periodontol. 2020, 91, 120-128. [CrossRef] 